\title{
The Role of Cloud Computing in Learning from a Logistic and Strategic Vision
}

\section{Case of Information Systems Management of a Private Moroccan University}

\author{
S.Bourekkadi ${ }^{1}$, S.Khoulji ${ }^{1}$, O.Omari ${ }^{2}$, K.Slimani ${ }^{3}$, A.Gamal ${ }^{1}$, M.L.Kerkeb ${ }^{1}$ \\ ${ }^{1}$ Department of Networking and Information Systems, National School of Applied Sciences, UAE \\ Tetouan, Morocco \\ ${ }^{2}$ Department of English, Moulay Ismail University, Faculty of Arts and Humanities \\ Meknes, Morocco \\ ${ }^{3}$ Ibn Tofail University, Faculty of Sciences, Kenitra, Morocco \\ acmlis.conference@gmail.com
}

\begin{abstract}
This research focuses on the role of cloud computing from a logistic and strategic vision in organizations. Our research question focuses on understanding the difficulties and limitations that bring the support of steering direction function of information systems in the use of cloud computing in an organization. An exploratory study was conducted with an organization. The results are presented in this article in which we start with an introduction concerning cloud computing. This article includes also an understanding of this effective solution. Meanwhile, our work involves also citing changes of the case study after using cloud computing emphasizing on financial and material gains. In brief, this article discusses one of the most important subjects in the field of management, methodology and management. Especially through the presence of ERP within companies which becomes a compulsory element and not one of the choices.

Keywords-component; Cloud Computing, logistics, strategic, ERP, information systems, business applications, multimedia.

\section{Introduction}

The 21st century has experienced a new form that will rediscover the technology of information. This new concept is considered as a better source of solutions to the problems encountered in companies regardless of their size. Here, we are talking about "Cloud Computing".

The principle of Cloud Computing is so simple, noting the following examples: storing photos, files, and data online (email or social networking website) instead of using a desktop. It is all about a cloud computing service. For instance, an organization that uses an online billing service instead of an in-house service, the online billing service is simply considered as a "cloud computing" service. The evolution of information technologies is significant in cloud computing. Cost reduction is a better argument for the providers who sell the cloud service. Users understand that corporate mobility benefits are the main advantage of a cloud computing movement. A study by Sand Hill found that $50 \%$ of respondents appreciate agility as the main reason for adopting cloud computing. A recent similar report according to
\end{abstract}


S.Bourekkadi, S.Khoulji, O.Omari, K.Slimani, A.Gamal, M.L.Kerkeb. The Role of Cloud Computing in Learning from a Logistic and Strategic Vision. Case of Information Systems Management of a Private Moroccan University. Transactions on Machine Learning and Artificial Intelligence, Vol 5 No 4 August (2017); p: 605-613

Information Week revealed that $65 \%$ of respondents also considered agility with respect to companies' needs as a motivation for cloud computing.

In fact, the main research question of this study is to know how can cloud computing help reduce costs while increasing the efficiency of the company? Hence, to have argumentative answers to this question we will analyze the research in three parts. At first, it seems wise to understand cloud computing. In a second step, we will use a survey on a well-known organization and analyze its existing state. This will allow us to discover in the third step, if the company decides to use cloud computing, what will be the benefits of this solution.

\section{Defining Cloud Computing}

In fact, Cloud Computing is the future of information technology. All major IT suppliers are investing their future revenues on cloud computing (Google, IBM, Microsoft, NASA, Adobe ...). Cloud Computing could lead to billions of dollars in energy savings.

Computing in a cloud or cloud computing is a major concept in the evolution of computing in the recent years. This concept refers to the use of computing and storage capacities of computers and servers distributed around the world and provided as a service through internet technologies to a multitude of external users.

The concept of Cloud Computing concerns the transfer of computer operations traditionally carried out on local computers to external servers. Thanks to cloud computing, users now have access to the various services that are managed online and become less complicated. The saved data is not on the local computer but in a cloud of remote servers interconnected by means of an excellent bandwidth essential to the fluidity of the system. That way, accessing the services is done via a web application that is standard and easily available.The tendency in information technology is "Cloud Computing" that characterizes computing in a network. In terms of outsourcing, companies use applications and data directly via the Internet through external interconnected servers of the organization. Then, companies find themselves free from a lot of information stored on their local posts. The cloud infrastructure contains several types of hardware components (servers, memory systems, network components, etc.), software application components (programs, services, protocols, etc.), and information.

A basic component of the cloud includes (Figure. 1):

- Technology architecture: It forms the first layer of the cloud platform (servers, operating systems, network tools, etc.).

- Application architecture: It is part of the functional layer and it includes all the business applications of the cloud platform.

- Information Architecture: This layer makes the cloud information available and ensures that it will be secure, consistent, and reliable. 


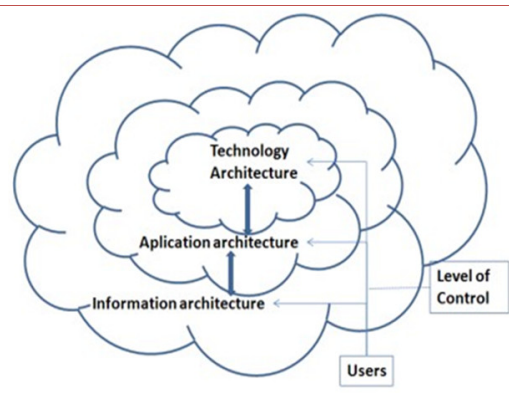

Figure 15 : The basic cloud computing architecture

According to the previous architecture scheme, a cloudplatform is able to provide:

- A completely independent infrastructure invisible to the final user;

- A platform capable of increasing its resources, if necessary, without the user being aware of it;

- An economical platform for the organization, reducing maintenance costs.

Meanwhile, the use of an ERP can be compatible with Cloud Computing if it is accessible in SaaS mode, and not in license mode. As a result, the company can access ERP applications directly on the Internet via remote servers where the data is stored.

Then, when we say ERP, we designate quite a module, among these modules we find:

1. Finance module.

2. Logistics module.

3. CRM module (GRC).

Indeed, the use of computing at the level of logistics becomes in our days among the principles of the IT. For this, we find a term that circulates between the computer scientists which is "logistics".

After all, how these two great jumps in technology can guide us to earn economically without touching the image of the organism, without losing the balance of the organization, and without becoming far from NICT especially that crises force companies to look for inexpensive solutions.

\section{Does cloud computing propose savings?}

While discussing the feasible savings that the Cloud offers, it is always necessary to do better with fewer budgets. Luckily, cloud computing services offer several financial benefits compared with other traditional systems.

\subsection{Less meetings}

The number of meetings and face-to-face meetings is significantly reduced through online service, collaborative writing, and discussion forums. For example, working on the same document remotely in collaboration with a team reduces the costs of moving people and saves time.

\subsection{Knowledge management}

The cloud is a good way to store data and share information within best practices, especially when a project is suspended or a department needs restructuring. Information here remains secure and centralized to the server. More importantly, it can be viewed and consulted by everyone whenever needed. 
S.Bourekkadi, S.Khoulji, O.Omari, K.Slimani, A.Gamal, M.L.Kerkeb. The Role of Cloud Computing in Learning from a Logistic and Strategic Vision. Case of Information Systems Management of a Private Moroccan University. Transactions on Machine Learning and Artificial Intelligence, Vol 5 No 4 August (2017); p: 605-613

\subsection{Coordination of shared services}

The costs are reduced when the management committee is grouped together (logistics, marketing, finance ...)

\subsection{Security access of the information}

The cloud makes work easier either at home, on the road or anywhere. Productivity and efficiency are increased by using mobile devices.

\subsection{Back on investment}

The investment is justified when all people appreciate the service and facilitate their work which eventually makes the company benefit.

\subsection{Security sharing of information}

Users can easily share their confidential information without worrying in a secure and accessible environment from anywhere.

\section{Exploratory study}

A study was conducted in an organization in the North of Morocco within the IT systems department. The following information illustrates the current case study: (See Table 1)

\subsection{Critical study}

\subsubsection{Materials:}

Each year the organization spends an amount of 7,000,000 DHS of equipment for the renewal of their equipment. However, the problem is the difficulty of getting rid of the parts that are out of service which are also dangerous for the environment and take a lot of space in the organization. These storage workshops are useful for other features instead of hardware accumulation. The organization has 800 printers, 300 of them in the back office, most back office printers are not fully used and it is better to use instead network printers.

\subsubsection{Quantitative of informatics park}

Like most big organizations, the company suffers from the permanent increase of their computer center by adding new services; thus, it is necessary to have a solution before reaching the maximum limit of the size of computer center.

\subsubsection{Software}

The organization uses Windows operating systems, office, and antivirus as basic software. The price of the operating systems is included with the computer, which increases their prices. The company has 1000 fixed licenses of Microsoft Office but only 250 are used per day. Hence, the solution is to replace them with floating licenses (for example 400 licenses will be sufficient), this will of course reduce the cost of the purchased licenses.

Meanwhile, the software located in the stations requires a permanent update using a high bandwidth and a high rate of collisions (network link failure). 


\subsubsection{Consumable}

The amount of annual energy consumption within the organization (electricity or fuel) is close to 800,000 DHS. The global crisis has forced companies to seek solutions to reduce consumable costs without increasing the quality of their service.

\subsubsection{Maintenance}

Maintenance is essential in the IT field but it is better to get rid of the daily problems in order to avoid reinventing the wheel.

Table 14 : The information about the experiment study

\begin{tabular}{|c|c|}
\hline \multicolumn{2}{|l|}{ Study of materials } \\
\hline Types of used materials & Desktop Pc, Laptop, Printer. \\
\hline Annual purchase (amount) & $7,000,000 \mathrm{DHS}$ \\
\hline Parts management (RAM, hard disk ...) & Stock in workshops: New part and Part out of service \\
\hline \multicolumn{2}{|l|}{ Quantitative study of the computer park } \\
\hline The state of computer center & The size increases permanently according to the portfolio of services \\
\hline \multicolumn{2}{|l|}{ Software study } \\
\hline Used software & Windows OS, Office, Antivirus \\
\hline Difficulty of use & Permanent problem of operation \\
\hline The amount of purchase & Included in the purchase of materials \\
\hline \multicolumn{2}{|l|}{ Consumable study } \\
\hline The consumption linked to the operation of the equipment & 720,000 DHS \\
\hline Diesel consumption due to technical team shifts & $72,000 \mathrm{DHS}$ \\
\hline \multicolumn{2}{|l|}{ Maintenance study } \\
\hline Contracts for maintenance & 120,000 DHS \\
\hline Inventory number & 3600 per site \\
\hline The most common problems & Material, software \\
\hline The number of technicians at HELPDESK & 17 on two sites \\
\hline
\end{tabular}

\subsection{Results analysis}

\subsubsection{Minimizing the cost of material}

By using Cloud Computing technology, we will no longer need a computer that costs 8,000 DHS; we will need only peripheral devices (case + screen) that cost just 1,700 DHS (4 times cheaper). This will reduce the cost of the annual purchasing by $78 \%$. (See Fig.2)

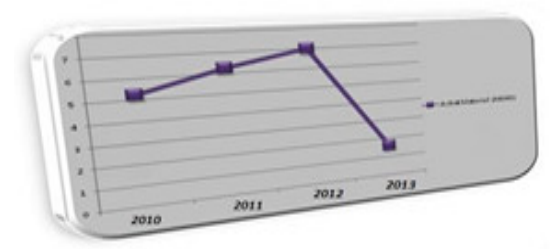

Figure 16. Evolution of the equipment cost

\subsubsection{Consumable costs reduction}

This is the most important thing when choosing a solution within the ISD, having an innovative project that gives added value to the company at a lower cost, at this moment there is no more project more efficient than Cloud Computing.

Cloud Computing offers a reduction in electrical consumables that can reach $50 \%$ using a Datacenter virtualization environment. Servers put on standby in charging State or Operating State. (see Fig. 3) 


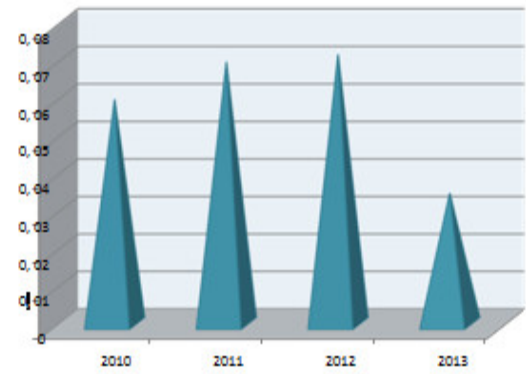

Figure 17. Consumable Equipment

\subsubsection{Maintenance cost}

Replacing computers with terminal devices (boxes) will eliminate maintenance contracts, the number of inventories per day will decrease, and software failure problems will disappear through the use of virtual desktops. Therefore, all this will increase the Quality of service offered by the company.

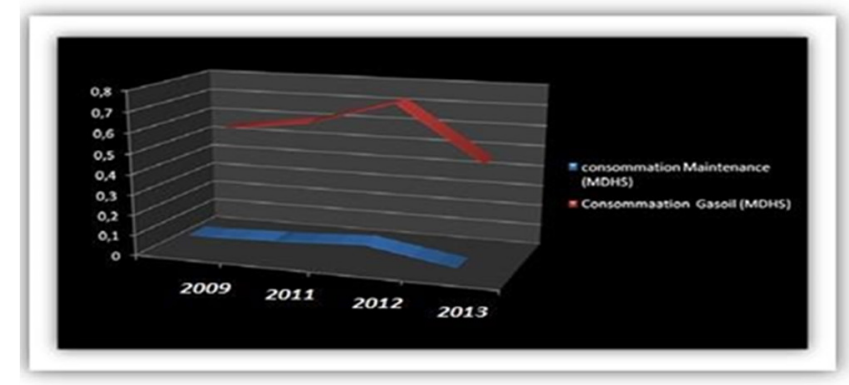

Figure 18 : Maintenance and fuel consumption

\subsubsection{Elimination of parts' management and stock}

By eliminating parts' management and the stock we will not need stock spaces that are useful in other functionalities; Moreover, we will save the dedicated amounts for the recycling of non-service parts.

Minimizing human and technical resources by using Cloud Computing, we will not need a large number of technicians because it will automatically decrease in relation to reduced technical resources. Virtualization will serve the solution of printing problems:

Printing is a permanent and indispensable service in the organization; precisely the printing of customer bills that are available and each incident gives a bad image within the organization.In implementing the Cloud Computing solution, we noticed that within the back office, the number of printers is 300 with only 50 printers used per day, plus the cost of paper and ink purchased in a random way.

For this reason, it has been proposed to set up a printer server within the Back office; a print server is a server that allows one or more printers to be shared between multiple users (or computers) on the same computer network.

This brings considerable and significant savings such as:

- Space saving

It is no longer necessary to buy one printer per user. This saves space, electricity, and maintenance. 
- Quick setup

Add a printer in few minutes. No need to cut your network connection.

- Flexibility, no queue or delay

Networking one or more printers can provide you with increased flexibility.

- Increased Cables Distance

The maximum recommended distance for a USB or Parallel printer is 5 meters. With the print server, you extend the connection length to 100 meters by connecting a printer directly, or 200 meters through a Switch or a network hub.

- Connection by cable category 5

Some modern buildings already have this type of wiring installed originally. It is easy to install it in case it is not installed.

- Model one or more ports according to your needs

If you need to connect more than one printer to your network, you can use multiport patterns. In this case, only one network port will be used.

\section{Results}

From the second year, students will be required to do practical work, download and buy Photoshop software, animation, flash, image games, and editing videos. Therefore, to use the 3D software it is better to have PCs with high quality and high capacity, such as i7 for example which can work with this software. So, with the solution Cloud Computing, it will be possible to buy a $700 \mathrm{DH}$ case with screens of $400 \mathrm{DH}$ that worth about 1,100 DH for each with the Cloud installed as a service. Hence, this will be much better than buying a PC of $17,000 \mathrm{DH}$.

For example, buying 10 licenses for 10 PCs will cost much more than installing the Cloud and purchasing only 5 licenses to work with the same number of PCs. Moreover, it will be possible to install, work, and use this software as a service and not as a product. We can also pay companies that will provide us with this monthly or annual product.

In addition, students who have not yet finished their work at school will be able to continue their work at home with the same application. Therefore, the access to the software will be online, that means all the work will be in cloud. This is why the ideal solution for like these issues is Cloud Computing.

\subsection{The financial gain}

According to the latest CSC survey, $82 \%$ of companies that have implemented a Cloud project have made financial gains. Thanks to the benefits provided to the company by the Cloud Computing solution.

A survey was done by the CSC based on a collection of 3465 users using Cloud Computing solution features due to the following reasons:

Instead of buying expensive hardware or software to use a particular program, Cloud Computing gives access to programs or applications centralized in servers and accessible to all users. The cost savings of not having to pay for equipment and programs that will quickly become obsolete will be extremely helpful to your budget. 
S.Bourekkadi, S.Khoulji, O.Omari, K.Slimani, A.Gamal, M.L.Kerkeb. The Role of Cloud Computing in Learning from a Logistic and Strategic Vision. Case of Information Systems Management of a Private Moroccan University. Transactions on Machine Learning and Artificial Intelligence, Vol 5 No 4 August (2017); p: 605-613

Some Cloud Computing services give the possibility to increase the processing power. Even when there is a need for increased processing capacities for a short period of time, it is possible to do it without having to invest heavily in expensive equipment based on Data center's virtualization technologies.

Large companies can use the cloud to endow the entire organization with tools that previously had to be installed on each computer, which wasted IT some time and was expensive. Meanwhile, companies will not need to renew their hardware based on recommended operating software and applications that save annual hardware purchases, inventory management, and recycling expenses for non-service materials.

\subsection{The material gain}

Cloud computing is a concept of deportation on remote servers of computer treatments traditionally performed on local computers, which does not recommend new software. With the Cloud Computing the client receives only an interface of the application that he/she uses and that is executed in the server. Cloud computing does not recommend high-performance hardware to customer support due to the installed software (an operating system + a web browser). The purchase of hardware is an indispensable task in big companies that apply the international standards of quality of services. This consists of the renewal of clients, servers etc., but it is not the same with Cloud Computing. The hardware purchase does not take into account customer support; there is a need of renewal of the servers in term of their life cycle and performance. However, despite the advantages, it is necessary to change the computer equipment every 4 years according to the age of depreciation.

\section{Conclusion}

To conclude, it was also possible to realize that the "IS" is an area in which it is necessary to work every day if we want to be able to keep up to date and to deepen one's knowledge. Indeed, new versions of the MSI tools come out regularly, each time with new features or improvements compared to the previous version. In addition, IT is a sector that is constantly evolving. Consequently, if we do not want to be overtaken too quickly, we have to keep up to date and for that there is only one solution, it is to work in a self-taught way very often. Cloud Computing ${ }^{2}$ is nowadays the most real cloud ever. It is a futuristic technology but it is current! If we were to summarize in a sentence what Cloud Computing is, we could say that it is a concept of deporting resources on remote servers in contrast to traditional hosting on the user station.

\section{ACKNOWLEDGMENT}

This work was supported by the grant of National Center for Scientific and Technical Research (CNRSTMorocco): No. 6UAE2015 and 757UIT for the first and the fourth authors.

We would like to express our gratitude and appreciation to Mrs. Nadia BOUMAZZOUGH, M. Marouan ELMHOUJEB, and M. Abdeljabar MAHDAR for their great inspiration, moral supports and their guidance. 


\section{REFERENCES}

[1] A. Sirotkin, Kaisa Koskela-Huotari, K. Karppinen, J. Del Ser, B. McCabe, "Differentiation in the Cloud: Methodology for Integrating Customer Values in Experience Design", Software Engineering and Advanced Applications (SEAA) 2012 38th EUROMICRO Conference on, pp. 453-459, 2012.

[2] Andreas Papadopoulos, Dimitrios Katsaros, "A-Tree: Distributed Indexing of Multidimensional Data for Cloud Computing Environments", Cloud Computing Technology and Science (CloudCom) 2011 IEEE Third International Conference on, pp. 407-414, 2011.

[3] Ximeng Liu, Robert H. Deng, Kim-Kwang Raymond Choo, Jian Weng, "An Efficient Privacy-Preserving Outsourced Calculation Toolkit With Multiple Keys", Information Forensics and Security IEEE Transactions on, vol. 11, pp. 2401-2414, 2016, ISSN 1556-6013.

[4] Jih-Sheng Chang, Ruay-Shiung Chang, "A performance estimation model for high-performance computing on clouds", Cloud Computing Technology and Science (CloudCom) 2012 IEEE 4th International Conference on, pp. 275-280, 2012.

[5] Chuang Deng, Junyong Liu, Yang Liu, Zhen Yu, "Cloud computing based high-performance platform in enabling scalable services in power system", Natural Computation Fuzzy Systems and Knowledge Discovery (ICNC-FSKD) 2016 12th International Conference on, pp. 2200-2203, 2016.

[6] Dinh, H. T., Lee, C., Niyato, D., \& Wang, P. "A survey of mobile cloud computing: architecture, applications, and approaches". Wireless communications and mobile computing, 13(18), 1587-1611, 2013. 